\title{
Research on the Specialization of Volunteer Service for Normalized Epidemic Prevention and Control
}

\author{
Yuqing $\operatorname{Sun}^{1, *}$ \\ ${ }^{1}$ School of Political Science and Law University of Jinan, Jinan, Shandong, China \\ *Email:843426052@qq.com
}

\begin{abstract}
The new crown pneumonia epidemic has brought challenges to social governance. In the face of the normalization of the epidemic, voluntary service is an important force in social governance. It is necessary to enhance their professionalism for governance to meet the needs of the epidemic. Volunteer services emphasizes specialization. What is needed is that volunteers have corresponding professional knowledge and skills, as well as the participation and guidance of professionals. In the field of epidemic prevention and control, it is more necessary to have professionalism in medical treatment and psychological counseling. Therefore, it is necessary to strengthen the training of volunteers, attract more professionals to participate in voluntary service, and encourage individual volunteers to improve their professional capabilities.
\end{abstract}

Keywords: Specialization, Volunteer Service, Epidemic Prevention and Control, Normalization

\section{INTRODUCTION}

Volunteer service is growing in our country. China's volunteer team is gradually growing, and the field and projects are also expanding. The scope of service covers social security, large-scale events, rescue and emergency rescue, poverty alleviation, environmental protection, community service, urban community construction, etc $^{[1]}$. All fields has long become an important force in social governance. In 2020, in the face of a sudden outbreak of new crown pneumonia, volunteers have come forward. In the 19th National Congress of the Communist Party of China, it was pointed out that it is necessary to improve the level of specialization of social governance, which provides guidance for the development of voluntary services, and its specialization has also aroused social thinking. Volunteer service in my country has a history of decades of development. Although previous studies have repeatedly mentioned the specialization of volunteer services, and in the prevention and control of the epidemic, which require grassroots personnel to have good professional capabilities. But there is no understanding of what specialization is, and clearly explained of the common and specific issues of specialization of voluntary services, especially the connotation and structural elements of specialization in combination with special volunteer service fields. Taking this opportunity, this article will take the normalization of epidemic prevention and control as an example to analyze the specialization of volunteer services, explore the connotation of specialization, and analyze the requirements and paths of specialization of voluntary service in epidemic prevention and control.

\section{THE PARTICULARITY OF THE SPECIALIZATION OF VOLUNTEER SERVICE}

\subsection{Specialization Rather than Professionalization of Volunteer Service}

The concept of professionalization originated from the West. It refers to the process by which an ordinary professional group gradually meets professional standards, becomes a specialized profession, and obtains corresponding professional status within a certain period of time $\left.{ }^{2}\right]$. It can be seen that the word "professionalization" is related to occupation has a close relationship, so it is not suitable to put it in the field of voluntary service. The "Volunteer Service Regulations" promulgated on August 22, 2017 stated that "volunteer service refers to the free public welfare services provided by volunteers, voluntary service organizations and other organizations to the society or others". Voluntary service organizations are non-profit 
organizations, and the services provided by volunteers are unpaid, which shows that it is difficult to associate volunteer services with professionalism. The voluntary services lies in the technical services provided by professional people or professional organizations that have professional or industry standards and corresponding norms for the public welfare voluntarily. Therefore, in the field of voluntary service, "specialization" is more accurate. It does not have the major constraints of professionalization, nor does it need to formulate professional standards or industry barriers. Instead, it requires volunteers to have corresponding professional knowledge and participation and guidance form skilled professionals.

\subsection{Connotation of Volunteer Service Specialization}

In the early days, volunteer services were mostly personal dedication and love, without any skills, and most of the volunteers were amateurs. However, with the development of society and the maturity of voluntary services, they have become an important social support force for the management and prevention of public health incidents. If voluntary services are to meet the diversified needs of society, they need to be transformed in the direction of specialism. Zhang Ke and Peng Qiaoyin pointed out that in the connotation of the specialization of youth volunteer services in colleges and universities, professional ethics are the core, professional skills are the foundation, professional image is the key, and professionalism evaluation is supplementary ${ }^{[3]}$. The specialization of volunteer service firstly lies in the professionalism of volunteers knowledge, specialised methods, voluntary organizations to introduce professionals, provide professional training, etc., specifically including three aspects of specialism in thought, action, and organization. Ideologically, it requires volunteers to have the professional spirit and philosophy of volunteer service, identify with the volunteer culture and abide by the rules and regulations of volunteer service, and engage in voluntary service with a serious attitude and willingness to contribute. There are two ways to make a volunteer team professional in action, one is the participation of experts, and the other is to provide training and guidance for volunteers, so that volunteers have service skills. In addition, voluntary organizations must also have organizational and management capabilities, be able to design scientific service plans for different voluntary services and allocate appropriate volunteers, ensure that services are more targeted, and allow limited resources to play an unlimited role.

\subsection{The Connotation of the Specialization of Voluntary Services for Epidemic Prevention and Control}

Epidemic prevention and control is a special field. In addition to the above-mentioned general characteristics, the specialism of volunteer services is also peculiar. This peculiarity is mainly reflected in methods and knowledge. First, volunteers need to have professional knowledge and skills for epidemic prevention and control, which include knowing how to conduct daily protection, understanding the characteristics and transmission of the new coronavirus, and knowing how to deal with suspected infections. Second, voluntary organizations need more specialised volunteers and training personnel who have professional knowledge of medical services, psychological counseling qualifications and emergency rescue experience. Third, volunteers must be familiar with the Internet and have the ability to provide online services, so that volunteer services such as psychological counseling should be carried out online to meet the long-standing epidemic's requirements for reducing personnel contact, and to provide high-quality voluntary services. Through the improvement of professionalism, volunteers should be able to accurately and clearly answer the questions of community residents in daily prevention and control propaganda, be able to protect themselves and others from being infected by the virus, and be able to provide precise services when they are needed by the client, so that they can make voluntary service truly specialised.

\section{THE INEVITABILITY OF VOLUNTARY SERVICE SPECIALIZATION IN NORMALIZED EPIDEMIC PREVENTION AND CONTROL}

\subsection{Normalized Prevention and Control Requires Specialised Volunteer Services}

Normalization indicates that society will be in the task of epidemic prevention and control for a long time, and voluntary services for epidemic prevention and control will also exist for a long time. Doing a good job in daily protection and monitoring, dealing with the problems of existing patients and preventing the outbreak of the epidemic is the focus of future work. Volunteer services will also focus on prevention. 疫 Volunteer service in the epidemic is different from ordinary volunteer service. First, it has a certain risk of infection due to long-term exposure to a large number of people moving. Secondly, in the face of elderly people with more knowledge of health and medical care, volunteers will have greater pressure and role embarrassment. And every time a similar incident is experienced, people's scientific and medical knowledge literacy will be significantly improved, and their 
experience in responding to the epidemic will also be richer. If there is no professional ability, volunteers may be relatively marginalized. Although it is a voluntary service, it is in the field of public health. Volunteers' service is more than simply distributing materials. Therefore, it must move from formalization to specialization to minimize risks and maximize service effects.

\subsection{Specialism to Improve the Efficiency of Voluntary Service}

The specialism of modern voluntary service is still lacking. Although most of the young volunteers with college students as the main body possess certain professional knowledge and skills, due to the limitations of age, knowledge and social experience, this knowledge and skills have relatively strong theoretical functions and have shortcomings in practice. In addition, volunteers are mostly recruited temporarily, and participation in public welfare activities is relatively random. The lack of stability and sustainability of the volunteer team is more prominent. The choice of volunteer service projects is also based on their own interests and does not consider the matching of personal abilities with actual needs. All these indicate that volunteers lack correct cognition of volunteer services. Research has found that current voluntary services have problems such as poor matching of effective supply and demand, and insufficient resource integration and sharing ${ }^{[4]}$. Professional loopholes make the services provided are often not targeted and efficient. However, normalized epidemic prevention and control has created a huge demand for volunteer services, and many new volunteer service fields and jobs have emerged. Service efficiency must be improved to meet these needs. All these have pushed volunteers to be more professional in cognition, knowledge and skills.

\subsection{Specialism can Establish Volunteer Authority}

There is a common phenomenon in modern society that people will first make subjective judgments about new information and new ideas. They are generally willing to believe and abide by what they think are right, and discard what they think is wrong or inconsistent with their common sense. In addition, there is no interest and power relationship between the two, and it is difficult to form a strong binding force. As a result, people refuse to cooperate and even conflict with them in the process of providing services and management by volunteers. To reduce or even solve this problem, it is necessary to build a good image of volunteers with specialism. Through suitable words and deeds, volunteers can play a demonstrative and leading role for the people around and the clients, giving people a sense of trust, thereby increasing their prestige and voice, and people will be more convinced and willing to obey the volunteers' arrangements, and then go to inspection and control will be more smooth.

\section{THE PATH TO PROMOTE THE SPECIALIZATION OF VOLUNTARY SERVICES FOR EPIDEMIC PREVENTION AND CONTROL}

First of all, professional training and systematic training of volunteers is the most direct and effective way to improve the specialism of volunteer services. The Fifth National Volunteer Training Teacher Training Program has improved the awareness and service ability of volunteers by offering a series of new era volunteer service courses and the form of exchange and sharing. It is also possible to set up a charity college, with the help of the government's promotion, the involvement of professional organizations and the participation of schools, to set up relevant charity courses to train volunteers.

Second, we must attract professionals to participate and form professional leadership. To improve the specialised level of social governance, we must first strengthen the construction of professional talents, ${ }^{[5]}$ Volunteer organizations should improve their own construction to attract professionals to participate in volunteer services, and use their influence drives more people into them. Through professional education, college students with a certain professional foundation can also be encouraged to engage in voluntary services similar to their own majors. In addition, professional service departments can also organize professionals to participate in voluntary services on a regular basis, and expand the team of specialised volunteers. For example, the "Stars Plan" launched by the Shandong Provincial Social Innovation Development and Research Center in March 2021 invites professionals from inside and outside the industry to provide more than 6 hours of voluntary services each year.

Finally, volunteers should improve their abilities. Volunteers must first have a correct understanding of volunteer service. And then, according to the characteristics of normalized epidemic prevention and control, the professional knowledge and skills to be learned to improve the specialism of volunteer services include the characteristics of the new crown pneumonia virus, prevention methods, emergency response methods, and basic communication skills and psychological knowledge, etc.

\section{CONCLUSION}

The outbreak of the new crown pneumonia epidemic has once again brought the issue of specialization of young volunteers to the attention of the society. Taking the peculiarities of volunteer services for epidemic 
prevention and control as an opportunity, higher requirements have been put forward for the specialization of volunteers. Promote the specialism of youth volunteer service, especially the medical professionalism, help epidemic prevention and control, improve the specialized level of social governance, and lay the foundation for the future development of voluntary service and point out the direction.

\section{REFERENCES}

[1]An Guoqi, Cao Kai. On the role of youth volunteer service in the social development of our country[J]. Chinese Youth Studies, 2002(1): 52-56.

[2] Xu Yongxiang. On the professionalization and specialization of community social work in my country[J]. Journal of East China University of Science and Technology, 2000(4): 56-60.

[ 3 ]Zhang Ke, Peng Qiaoyin. Research on the Specialization of University Youth Volunteer Service[J]. Chinese Youth Studies, 2010(02): 43-46.

[4]Tu Minxia, Peng Minggang, Wu Donghua, Feng Yingzi. Research Report on Volunteer Service Optimization Model Driven by Big Data[J]. Chinese Youth Research, 2020(04): 62-68.

[ 5 ]Zhou Hanhua. Specialization is an inevitable requirement [N]. People's Daily, 2017-11-01 (19). 